ИЗВЕСТИЯ АКАДЕМИИ НАУК ЭСТОНСКОИ ССР. ФИЗИКА * МАТЕМАТИКА

PROCEEDINGS OF THE ACADEMY OF SCIENCES OF THE ESTONIAN SSR.

PHYSICS * MATHEMATICS

$1988,37,2$

\title{
СПЕКТРАЛЬНО-КИНЕТИЧЕСКОЕ ИССЛЕДОВАНИЕ ВЫСОКОТЕМПЕРАТУРНЫХ СВЕРХПРОВОДЯЩИХ КЕРАМИК Ү-Ва-Сu-O ПРИ УЛЬТРАФИОЛЕТОВОМ ЛАЗЕРНОМ ВОЗБУЖДЕНИИ
}

S. SAVIHHIN, H. SONAJALG, A. FREIBERG. Y-Ba-Cu-O-TOOPI KORGETEMPERATUURILISTE ULIJUHTIVATE KERAAMIKATE SPEKTRAAL-KINEETILINE UURIMINE ULTRAVIOLETSEL LASERERGASTUSEL

S. SAVIKHIN, H. SONAJALG, A. FREIBERG, THE SPECTRAL AND KINETIC STUDY OF HIGHTEMPERATURE SUPERCONDUCTIVE CERAMICS $\mathrm{Y}-\mathrm{Ba}-\mathrm{Cu}-\mathrm{O}$ AT ULTRAVIOLET LASER EXCITATION

\section{(Представил В. Хиюняков)}

Недавно сообщалось об обнаружении низкотемпературной фото- и катодолюминесценции сверхпроводящих при $T<95 \mathrm{~K}$ керамик $\mathrm{YBa}_{2} \mathrm{Cu}_{3} \mathrm{O}_{x}$ [ $\left.{ }^{1}\right]$. Общая картина спектра люминесценции оказалась сложной. Наиболее яркая особенность спектра свечения керамик узкая линия люминесценции 3,355 эВ - проявлялась как при возбуждении электронами, так и фотонами $[1,2]$. Она интерпретирована как результат излучательной рекомбинации электронов со сверхпроводящим куперовским коллективом спаренных дырок $\left[{ }^{1,2}\right]$. Не исключена также возможность, что часть свечения в области спектра 3,383,25 эВ (в том числе свечение 3,355 эВ $\left[{ }^{3}\right]$ ) имеет альтернативное объяснение как экситонное свечение в микрофазе окиси цинка, присутствующей в малом количестве из-за загрязненности исходного материала $\mathrm{CuO}$ ионами $\mathrm{Zn}^{2+}\left[{ }^{2}\right]$.

Настоящая работа предпринята для более однозначного выяснения природы наблюдаемых в сверхпроводящих керамиках $\mathrm{YBa}_{2} \mathrm{Cu}_{3} \mathrm{O}_{x}$ свечений путем совместного исследования спектральных и кинетических свойств фотолюминесценции при возбуждении ультрафиолетовыми лазерными импульсами пикосекундной длительности. Объекты в виде спрессованных таблеток (аналогичных исследованным в $\left[{ }^{1,2}\right]$, а также $\mathrm{EuBa}_{2} \mathrm{Cu}_{3} \mathrm{O}_{x}$ ) проверяли на наличие эффекта Мейснера и помещали в гелиевый криостат. Средняя мощность возбуждения на длине волны около 309 нм (вторая гармоника лазера на красителе родамин 6Ж) составляла $\sim 0,5$ мВт, пиковая 2 Вт при частоте следования импульсов 82 МГц и длительности импульсов 3 пс. Кинетика свечения детектировалась синхронно сканируемым электронно-оптическим преобразователем. Подробно экспериментальная аппаратура описана в $\left[{ }^{4}\right]$.

На рис. 1 представлен характерный спектр весьма слабого свечения, полученный нами при температуре $4 \mathrm{~K}$ для $\mathrm{YBa}_{2} \mathrm{Cu}_{3} \mathrm{O}_{x}$ (спектр $\mathrm{EuBa}_{2} \mathrm{Cu}_{3} \mathrm{O}_{x}$ по форме не отличался от спектра $\mathrm{YBa}_{2} \mathrm{Cu}_{3} \mathrm{O}_{x}$ ). Вид этого спектра в общих чертах совпадает с видом спектра фотолюминесценции, приведенного в работах $\left[{ }^{1,2}\right]$, однако положение максимума узкой полосы свечения с полушириной 6 мэВ несколько отлично - 3,367士 $\pm 0,001$ эВ вместо 3,355 эВ, а также отсутствует длинноволновая полоса 


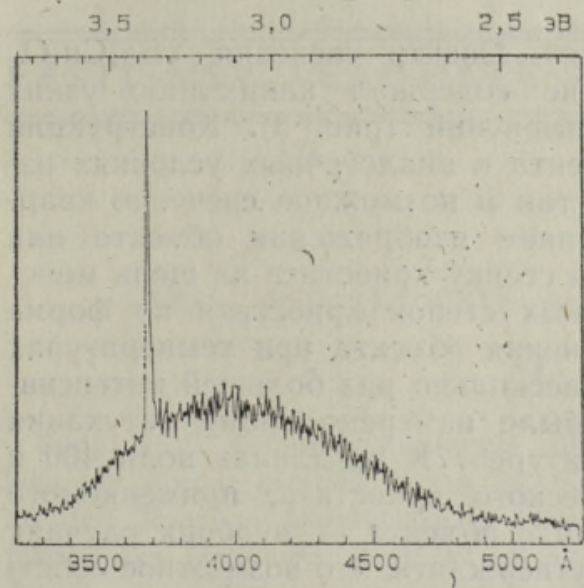

Рис. 1. Спектр свечения $\mathrm{YBa}_{2} \mathrm{Cu}_{3} \mathrm{O}_{x}$ в металлическом криостате при температуpe $4 \mathrm{~K}$ и длине волны возбуждения 309 нм.

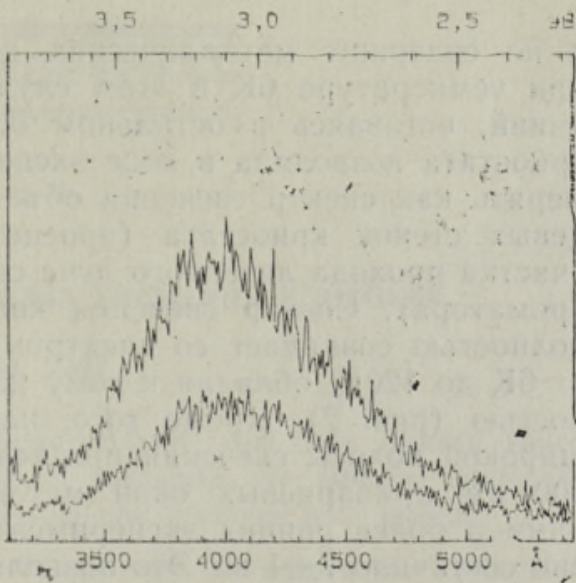

Рис. 2. Спектр свечения стенок кварцевого криостата при фокусировании лазерного луча на стенку (верхняя кривая) и на объект в нем (нижняя кривая) при температуре $6 \mathrm{~K}$ и длине волны возбуждения 309 нм.

около 2,3 эВ $\left[{ }^{1,2}\right]$. Удалось измерить также время затухания свечения 3,367 эВ, оно составило приблизительно 70 пс.

Ввиду слабости наблюдаемого сигнала и его чувствительности к геометрии эксперимента (в том числе положению сфокусированного лазерного луча на поверхности объекта), а также природы объекта особое значение приобретает учет возможных следов фаз различных окислов на поверхности объекта. Кроме того, при сильно рассеивающих объектах следует исключить возбуждение различных деталей криостата, что особенно существенно при ультрафиолетовом возбуждении.

Эксперименты с прессованными таблетками $\mathrm{CuO}$ и монокристаллическим объектом $\mathrm{CuO}_{2}$ доказали непричастность этих фаз к линии 3,367 эВ (интенсивность линии не увеличилась). Однако узкая линия с аналогичными спектрально-кинетическими параметрами (энергетическое положение 3,367 эВ, время нарастания свечения $\sim 20$ пс, время затухания $\sim 70$ пс), но с интенсивностью на 3-4 порядка бо́льшей, обнаружена нами при возбуждении в гелиевом криостате пластины из технической латуни, покрытой слоем естественной окиси. В то же время интенсивность свечения свежей отполированной поверхности латуни более чем на два порядка меньше, а в случае свежеполированной меди практически отсутствует.

Совокупность результатов проведенных экспериментов в согласии с гипотезой, высказанной в $[2,3]$, указала на окись цинка как на возможный источник регистрируемого свечения. Контрольные спектрально-кинетические измерения, проведенные на монокристаллическом образце $\mathrm{ZnO}$ (о них будет сообщено отдельно) подтверждают данный вывод. Они позволяют интерпретировать линию 3,367 эВ как линию свечения локализованного на ионизированном доноре экситона в окиси цинка (традиционное обозначение $I_{2}, I_{3}\left[{ }^{5}\right]$ ). В пользу такой интерпретации говорит и быстрый спад интенсивности люминесценции локализованных экситонов при температурах выше $20 \mathrm{~K}\left[{ }^{6}\right]$, аналогичный спаду, наблюдаемому в $[1,2]$. Это объясняет также появление в спектре свечения некоторых керамик дополнительно узкой линии 3,31 эВ - такая линия существует и в спектре окиси цинка $\left[{ }^{5}\right]$.

Для устранения возможного свечения латунных деталей используемого нами криостата таблетка $\mathrm{YBa}_{2} \mathrm{Cu}_{3} \mathrm{O}_{x}$ была помещена в гелиевый криостат, объектная часть которого изготовлена из кварцевой трубы 
и не содержит металлических деталей. Спектр свечения $\mathrm{YBa}_{2} \mathrm{Cu}_{3} \mathrm{O}_{x}$ при температуре $6 \mathrm{~K}$ в этом случае не содержал каких-либо узких линий, оставаясь в остальном без изменений (рис. 2). Конструкция криостата позволяла в ходе эксперимента в аналогичных условиях измерять как спектр свечения объекта, так и возможное свечение кварцевых стенок криостата (проецированием изображения объекта или участка прохода лазерного луча сквозь стенку криостата на щель монохроматора). Спектр свечения кварцевых стенок криостата по форме полностью совпадает со спектром свечения объекта при температурах от $6 \mathrm{~K}$ до $120 \mathrm{~K}$, обладая к тому же в несколько раз большей интенсивностью (рис. 2). Кроме того, нами было измерено время затухания широкой полосы свечения при температуре $77 \mathrm{~K}$ на длинах волн 400 и 500 нм с кварцевых окон металлического криостата; применяемого нами в более ранних экспериментах, и с объекта - в обоих случаях оно составило $7 \pm 1$ нс. Это позволяет утверждать, что возможное собственное свечение $\mathrm{YBa}_{2} \mathrm{Cu}_{3} \mathrm{O}_{x}$ при используемом возбуждении по крайней мере на порядок меньшей интенсивности. т. е. имеет квантовую эффективность не более $10^{-7}$ из расчета на 1 нм (что на 2 порядка меньше, чем в $\left.\left[{ }^{2}\right]\right)$, а наблюдаемый нами сигнал обусловлен свечением стенок и кварцевых окон криостата, возбуждаемых рассеянным от объекта ультрафиолетовым лазерным светом. Однако при возбуждении $\mathrm{YBa}_{2} \mathrm{Cu}_{3} \mathrm{O}_{x}$ при температуре $120 \mathrm{~K}$ (для исключения влияния свечения криостата объект охлаждался потоком холодного азота на воздухе) излучением более мощного эксимерного ХеСl-лазера (средняя мощность на 308 нм 2 мВт, пиковая $\sim 10$ кВт) в спектре люминесценции получена широкая полоса с максимумом около 500 нм, шириной на полувысоте 150 нм и интегральной квантовой эффективностью $\sim 2 \cdot 10^{-8}$. При нагревании объекта до комнатной температуры интенсивность свечения падает в 3 раза. Данная полоса, по-видимому, составная, о чем говорит сложная кинетика свечения - удовлетворительное описание экспериментальной кривой в мс диапазоне времен достигается лишь при использовании трех констант затухания (1, 6 и 60 мс; измерено в режиме счета фотонов). Ее природа еще до конца не выяснена.

В заключение выражаем благодарность Ч. Лущику, А. Маароосу и T. Авармаа за любезное предоставление таблеток $\mathrm{YBa}_{2} \mathrm{Cu}_{3} \mathrm{O}_{x}$, Ч. Лущику за многократное полезное обсуждение природы узкой полосы свечения, Р. Кинку за обсуждение спектров, полученных при возбуждении эксимерным лазером и синхротронным излучением, а также за обсуждение соответствующей методики эксперимента, Ю. Колку за предоставление кварцевого криостата и помощь при работе с ним, П. Кукку за участие в экспериментах с применением эксимерного лазера, П. Саари за стимулирующий интерес и поддержку.

\section{Л И Т Е Р А Т Р А}

1. Лущик Ч. В., Куусманн И. Л., Фельдбах Э. Х., Валласте К. Э., Либлик К. Э., Маароос А. А., Мерилоо И. А., Савихина Т. И. Письма в ЖЭТФ, 46, 122124 (1987).

2. Лущик Ч. Б., Куусманн И. Л., Фельдбах Э. Х., Либлик П. Х., Савихина Т. И., Мерилоо И. А. ФТТ, 29, 3667-3672 (1987).

3. Лущик Ч. Б., Куусманн И. Л., Кузнецов А. И., Фельдбах Э. Х. Изв. АН СССР, сер. физ., 52, 685-690 (1988).

4. Анияле А. О., Тимпманн К. Э., Фрейбере А. М. Письма в ЖЭТФ, 23, 1461-1464 (1982).

5. Кузьмина Н. П., Никитенко В. А. Окись цинка, получение и оптические свойства. М., «Наука», 1984.

6. Filinski, I., Skettrup, T. Solid. State Commun., 6, 233-237 (1968). 